Dialectologia 26 (2021), 1-26.

ISSN: 2013-2247

Received 15 March 2019.

Accepted 3 July 2019.

\title{
THE EFFECTS OF AGE AND GENDER ON THE PERCEPTIONS OF LINGUISTIC VARIATION IN THE QASSIMI ARABIC DIALECT
}

\author{
Yousef AL-ROJAIE \\ Qassim University * \\ yrojaie@qu.edu.sa
}

\begin{abstract}
This article examines the effects of age and gender on perceptions that speakers of Qassimi Arabic, a variety of Najdi Arabic spoken in central Saudi Arabia, have of the placement and extent of dialect areas marked on hand-drawn maps representing variation within their own dialect. Analysis of composite maps of respondents' perceptions using a GIS mapping program (ArcGIS) reveals that both age and gender have an effect on respondents' perceptions of linguistic landscape. Specifically, men tend to distinguish more linguistic variation by identifying more dialect areas than women do. As for age differences, middle-aged respondents identified more dialect areas with higher agreement levels than both younger and older respondents. These patterns of variation among age and gender groups can be attributed to differences in the local traditional society in terms of contact and geographic mobility, particularly following the socioeconomic changes that Saudi Arabia has experienced in the past half-century.
\end{abstract}

\section{Keywords}

perceptual dialectology, linguistic variation, GIS, dialect boundaries, Arabic dialects

\footnotetext{
* Department of English \& Translation, College of Arabic \& Social Studies, Qassim University, Buraydah, Qassim, 52571-7608, Saudi Arabia.
} 


\section{LOS EFECTOS DE LA EDAD Y EL GÉNERO EN LAS PERCEPCIONES DE LA VARIACIÓN LINGÜÍSTICA EN EL DIALECTO ÁRABE QASSIMI}

\section{Resumen}

Este artículo examina los efectos de la edad y el género en las percepciones que los hablantes de árabe qassimi, una variedad de árabe najdi que se habla en el centro de Arabia Saudita, tienen sobre la ubicación y extensión de las áreas dialectales marcadas en mapas dibujados a mano que representan variación dentro en su propio dialecto. El análisis de mapas compuestos de las percepciones de los encuestados utilizando el programa ArcGIS revela que tanto la edad como el género tienen un efecto en las percepciones del paisaje lingüístico de los encuestados. En particular, los hombres tienden a distinguir más variaciones lingüísticas al identificar más áreas dialectales que las mujeres. En cuanto a las diferencias de edad, los encuestados de mediana edad identificaron más áreas dialectales con niveles de acuerdo más elevados que los encuestados jóvenes y mayores. Estos patrones de variación entre grupos de edad y género se pueden atribuir a diferencias en la sociedad tradicional local debidas al contacto y a la movilidad geográfica, particularmente después de los cambios socioeconómicos que Arabia Saudita ha experimentado en el último medio siglo.

\section{Palabras clave}

dialectología perceptual, variación lingüística, SIG, límites dialectales, dialectos árabes

\section{Introduction}

A substantial body of previous research in the field of sociolinguistics has been devoted to investigating the perceptions that nonlinguists have of social and regional linguistic variation and its spatial distribution (e.g., Benson 2003; Bucholtz et al. 2007, 2008; Inoue 1996; Hartley 1999, 2005; Preston 1986, 1989). In such studies, researchers employed a set of tasks, including hand-drawn maps, to elicit respondents' mental representation of regional dialect varieties. The primary focus of these studies was exploring respondents' perceived placement and extent of dialect areas, along with the associated beliefs and attitudes about their speakers and varieties.

More recently, with the advent of new computerized technologies that can be used to process and aggregate large geographical data collected form hand-drawn map tasks, several studies (e.g., Cramer 2010; Cukor-Avila et al. 2012; Evans 2011, 2013; Jeon 2013; Montgomery \& Stoeckle 2013) have been carried out using mapping software programs based on Geographic Information Systems (GIS). The aggregated data in such programs 
can also be queried, providing the researchers with a variety of ways to analyze and visualize the quantitative and qualitative data and thus revealing patterns that would be difficult to map and calculate using traditional techniques (Evans 2013).

Despite the potential advantages of adopting such mapping programs, particularly in direct comparison research, very few studies have examined the effect of social factors such as age, gender, and class on respondents' identification of dialect areas and evaluation (cf., Jeon 2013, Alrumaih 2002). The significance of such social factors has been demonstrated in numerous studies of how they shape the ways language is produced, and it would be possible if they have similar effects in perception-based studies. Moreover, most previous studies examined perceptions of language variation in countries such as the United States, United Kingdom, Japan, France, South Korea, China, and Turkey (e.g., Demirci \& Kleiner 1998, Jeon 2013, Kuiper 2005, Long 1999, Niedzielski \& Preston 2000, Yan 2015), and little attention has been paid to Arabic dialects in general and specifically in Saudi Arabia.

The present study is intended to address this gap in the literature by exploring the effect of social factors, namely age and gender, on the perceptions of regional dialect variation in Qassimi Arabic (hereafter QA), a variety of Najdi Arabic, spoken mainly in the Qassim province (henceforth Qassim) in central Saudi Arabia (see Map 1). This study is motivated by the need to further explore our understanding of the underlying local ideologies and social meanings that age and gender groups consider in perceiving dialect differences in a relatively small region rather than an entire country. This study would potentially provide a detailed and deeper understanding of the local ideology by the social groups in question.

\section{Perceptual dialectology}

The study of perceptual dialectology (hereafter PD) is concerned with exploring nonlinguists' perceptions of linguistic variation. The field of PD began in the $19^{\text {th }}$ Century and has been developed extensively in the mid- $20^{\text {th }}$, particularly in the Netherlands and 
Japan (Preston 2017: 177). Interest in PD has enjoyed a revival in the late 1990s following Preston's studies on U.S. English varieties (e.g., Preston 1989, 1993, 1996, 1999), which refocused the attention in language variation research on nonlinguists' perceptions of regional dialectical variation. According to Hachimi (2015: 37), the field of PD has emerged largely in reaction to (1) the dominance of production over perception-oriented approaches to language variation studies in earlier traditional dialectology research, (2) the frequent privilege granted to linguists' views without regard for non-linguists' own perceptions, and (3) failings in earlier social psychological studies of attitudes due to failing to address respondents' awareness of the link between the voices they evaluate and the place these voices are coming from.

The inclusion of PD in linguistic studies provides important insights into the description and analysis of language variation and change. It connects, for example, how language varieties are actually produced and how the nonlinguist speakers of these varieties perceive them, and that combination leads to a complete picture of the actual patterns of variation in these varieties. It also highlights the social meanings and sociocultural associations that nonlinguists attach to linguistic variants and their spatial distribution (Evans 2013). This, in turn, provides an understanding of the underlying meanings of variation that would not often be gained from production linguistic studies. Additionally, it provides an opportunity for researchers to examine linguistic features seldom addressed or sometimes unnoticed in previous studies (e.g., Evans 2011).

In response to calls to incorporate PD in linguistic research, scholars conducted a series of research studies using the perceptions-oriented approach to examine regional English dialect perceptions in the United States (e.g., Hartley 1999; Benson 2003; Bucholtz et al. 2007, 2008; Evans 2011, 2013) and the United Kingdom (e.g., Inoue 1996; Montgomery 2007). PD approaches have also been applied to study language variation in languages around the world, including Japanese (Long 1999), Chinese (Yan 2015), French (Kuiper 2005), Korean (Jeon 2013), and Turkish (Demirci \& Kleiner 1998; Demirci 2002), among many others.

Drawing on research techniques from cultural geography, PD presents a set of research techniques to elicit respondents' perceptions of linguistic variation. The most widely used tools in PD research are two related techniques: draw-a-map and labeling 
tasks. The draw-a-map method is straightforward: Respondents are provided with a minimalistic map and asked to hand-draw boundaries around dialect areas where they believe people speak differently. Afterward, respondents are instructed to label the handdrawn areas they identified on maps with a descriptive label. The advantage of using these techniques is that they elicit respondents' mental maps as well as the social meanings and sociocultural serotypes they attach to the varying dialects they distinguish. Such elicitations may not be as explicit in other research techniques or social interactions (Preston 2004, as cited in Hachimi 2015).

Results of previous PD studies have revealed that respondents are generally very aware of sociolinguistic patterns within their own variety. Respondents were also found to recognize linguistic differences similar to those identified by professional linguists (Evans 2011; Hachimi 2015), and they could occasionally identify linguistic features researchers addressed in a limited fashion (Evans 2011). Furthermore, respondents were found to have the perceptual abilities in identifying and recognizing linguistic differences within a language variety, "but also in detecting subtle differences in specific linguistic markers of variety" (Preston 2017: 200).

To process large numbers of hand-drawn maps generated out of 'draw-a-map' tasks, recent PD research studies (e.g., Montgomery 2007; Cramer 2010; Cukor-Avila et al. 2012; Montgomery \& Stoeckle 2013; Evans 2011, 2013; Jeon 2013) have employed Geographic Information Systems (GIS) mapping programs. Montgomery \& Stoeckle (2013: 24) summarized the benefits of using such programs: (1) improving the quality of visualization tools available to PD researchers, (2) combining individual areas on the same map, (3) customizing aggregate data, and (4) performing calculations and statistical analyses. As such, it is possible, for example, to compare the aggregate maps drawn by different social groups of respondents in terms of their mental maps of linguistic variation as well as by the subjective labels they provide for the varying dialects they distinguish.

Within the context of Arabic sociolinguistics, the study of PD to language variation has been given very little attention. A thorough search of the relevant literature yielded only three related PD studies that examined linguistic variation in Arabic dialects. The first and most related study is Alrumaih (2002), who examined the perceptual dialectology of 
60 speakers of Najdi Arabic, spoken in central Saudi Arabia, using five research tasks: draw-a-map, degree-of-correctness, degree-of-pleasantness, degree-of-difference, and structured interviews. He also examined the effect of age and gender on respondents' perceptions. Results of the draw-a-map task revealed that Najdi respondents identified five distinct dialect areas within Saudi Arabia: the Central region, the Western region, the Eastern region, the Northern region, and the Southern region.

The second study was conducted in Qatar, where Theodoropoulou \& Tyler (2014) examined the folk perceptions about dialectical variation within the Arab world among female undergraduate students. Results demonstrated that participants grouped Arab dialect into five categories: the Maghreb, Egypt and Sudan, the Levant, the Gulf, and Somalia. Although the study presented interesting results, it was limited to younger female respondents.

In Morocco, Hachimi (2015) conducted the most recent PD study about Moroccan Arabic speakers' attitudes and hierarchies of Arabic dialects in the Arab World. Findings demonstrated that respondents' boundaries of regional Arabic dialects were similar to those defined by linguists. Moreover, analysis of the results revealed that Syrian Arabic was considered the "best Arabic" to Moroccan respondents based on a range of attitudes and ideologies.

\subsection{The effect of age and gender on language perceptions}

While there is a plethora of previous studies in variationist sociolinguistics that investigated the effect of social factors, particularly age and gender, using productionbased approaches (e.g., Labov 2001, Eckert 2000), there are a very few attempts to uncover the effect of age and gender in perceiving language variation. Demirci \& Kleiner (1998) examined age and gender-based differences in the perception of linguistic variation in Turkish dialects. Results revealed that both age and gender factors impacted respondents' evaluation of dialects in terms of correctness and pleasantness. Specifically, by comparing gender groups, men were found to give higher ratings than women in terms of the correctness and pleasantness of the speech. As for age differences, older respondents were more likely to assign the highest ratings for correctness and 
pleasantness, while middle-aged respondents were consistent in assigning the lowest ratings. In a subsequent study using the same data, Demirci (2002) compared men and women in their identification of different dialect areas in Turkey. He found that men perceived far more dialect areas than women. These results were explained as a reflection of the traditional and male-dominant society in Turkey, whereby women are less mobile and have limited access to social and work institutions. However, in his study of Najdi speakers' perceptions of dialectical variation within Saudi Arabia, Alrumaih found no significant effect in both age and gender.

In her thesis about Koreans' perceptions of language variation, Jeon (2013) examined, among other things, the differences among age and gender groups in perceiving language differences in Korea, particularly in identifying salient dialect areas using the draw-a-map technique. Analysis of the results suggested that both age and gender have an effect on respondents' perceptions. As for age, analysis of the composite maps indicated that the identification of dialect areas correlated with the age of respondents, wherein older respondents identified more dialects with finer-grained distinctions of different dialects compared with middle-aged and younger respondents, respectively. Regarding age differences, the results of the analysis of composite maps revealed that women identified more salient dialect areas with higher levels of granularity compared to men.

\subsection{The current study}

As reviewed in the literature above, the study of nonlinguists' perceptions about linguistic variation in Arabic dialects in general and Saudi Arabian dialects in specific has been given little attention. Additionally, the effect of social factors, such as age, gender, and education level, has not been explored thoroughly in previous PD research, especially in a speech community of QA, where the linguistic situation is hitherto unresearched in linguistic and attitudinal studies. Added to this, the socioeconomic changes that Saudi Arabia has undergone in the past 50 years, which presumably have influenced the linguistic landscape in Qassim, would merit further investigation. 
Therefore, the present study seeks to answer the following research questions:

1. Do age and gender have an effect on QA speakers' perceptions of linguistic variation within QA in their identification of boundaries of dialect areas?

2. Do age and gender have an effect on QA speakers' perceptions of linguistic variation within QA in terms of the subjective labels and sociocultural associations that they attach to different dialect areas?

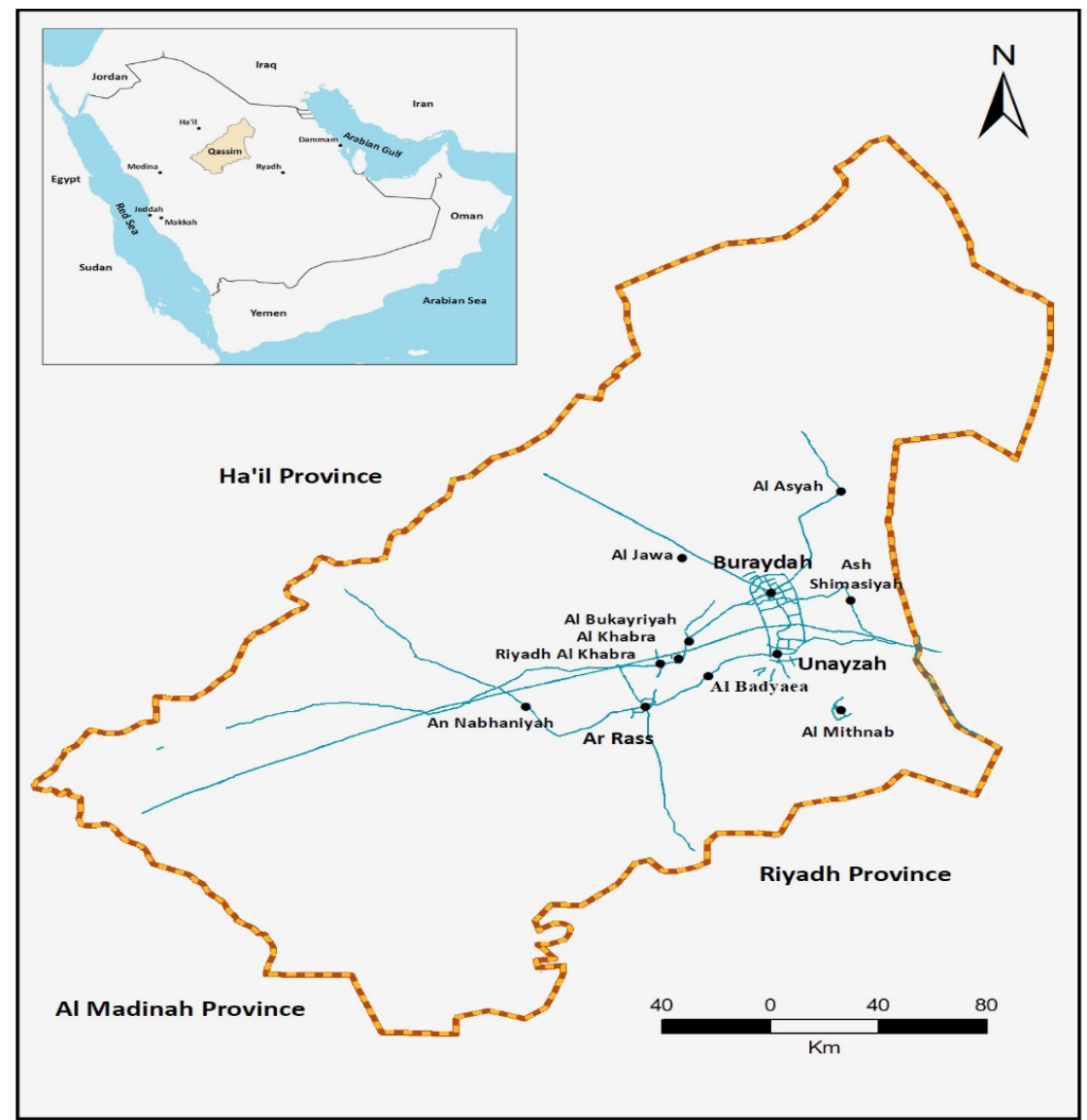

Map 1. The location of Qassim in Saudi Arabia (upper-left corner); a map of the Qassim province with its main cities (center).

\section{Qassim: social and linguistic situation}

Qassim is located in the north-central part of Najd, central Saudi Arabia (see Map 1), situated nearly $300 \mathrm{~km}$ northwest of Riyadh, the capital of Saudi Arabia. It comprises 13 
counties: Buraydah, Unayzah, Ar Rass, Al Mithnab, Al Bukayriyah, Al Badayea, Al Asyah, An Nabhaniyah, Al Jawa, Riyadh Al Khabra, Ash Shimasiyah, Uglat Asugour, and Dhariyah. Buraydah is the regional administrative capital of Qassim and the most populous city. The population of Qassim is over 1 million (based on 2010 census), and more than half reside in Buraydah.

Following the socioeconomic changes that Saudi Arabia has experienced in the last half a century, the people in Qassim have transformed almost all aspects of their lives in a rapid and dramatic process of urbanization and modernization. A very related and crucial consequence of such changes was increased dialect contact with speakers of other dialects inside and outside Qassim through social and geographic mobility; men, in particular, had this exposure as a result of work, business, and travel. Such increased contact and mobility not only raised their awareness of regional variations but also contributed to a linguistic change. In a recent study, Al-Rojaie (2013) examined the effect of age, gender, and level of education on the patterns of variation in the use of the affrication of [ts] for [k]. The results showed a significant correlation between the process of deaffrication of $[\mathrm{k}]$ and the age, gender, and level of education of the speaker, where younger and middle-aged educated women are leading the shift toward the use of the regional variant. This change, as argued by Al-Rojaie, was triggered and accelerated by the socioeconomic changes, where the newly adopted variant is increasingly associated with urbanity and modernization.

The Arabic dialects spoken in Qassim are varieties of Najdi Arabic, spoken in a wide area across central Saudi Arabia. There are two main types of dialects spoken in Qassim: the Qassimi dialect (QA) and the tribal dialects. The $\mathrm{QA}^{1}$ is mainly spoken by the sedentary (locally called haḍari) population (Ingham, 1994), whereas the tribal dialects (sometimes called Bedouin) are used by tribal members affiliated with certain tribes, including Ḥarb, Muțair, Rashid, 'Utaiba, and 'Anizah, as well as other smaller tribes. The sedentary people were the first settlers in Qassim, including many families who migrated

\footnotetext{
${ }^{1}$ The QA name is derived from the adjective form of the province label, Qassim. Similarly, the sedentary speakers of QA are commonly called throughout the kingdom by the name of the province using terms like Qusman, ahlu al Qassim, and sometimes with the vernacular name Qusmanji (sg.) and rarely with Qusmanj (pl.)
} 
from different towns in neighboring regions in Najd at various times and stages throughout the past few centuries. They established most of the cities and villages across the region, with the exception of some towns in the western and southwestern parts, particularly in the counties of Uglat Asugour and Dhariyah. To a large extent, speakers of tribal dialects maintained the use of their own dialects even after settlement in sedentary dwellings $^{2}$ (Al-Ubudi 1979, Al-Jumaah 2017). As the focus of the current study is on the $Q A$, the next sections will be limited its linguistic features.

Currently, the QA is mainly spoken in urban centers and villages inhabited by the sedentary population (Al Ubudi 1979). Al-Jumaah (2017: 43) specifically identified four major cities where QA is dominant: Buraydah, Unayzah, Ar Rass, and Al-Bukayriyah, as well as other smaller towns and villages largely inhabited by sedentary people, including Al-Badayea, Al-Khabra, Riyadh Al-Khabra, Ash Shimasiyah, and Al-Mithnab. However, he excluded Uyun Al Jawa and its neighboring smaller towns ${ }^{3}$ in the Al Jawa County on the northern side of Qassim, as well as Al Asyah ${ }^{4}$ County in the northeast part of Qassim (see Map 1), on the basis that their speech exhibited linguistic features not common with QA speakers. Based on traditional dialectology accounts of QA (e.g., Al-Jumaah 2017, Al Ubudi 1979), the differences among QA speakers is very slight, and lay people (the "folk") often fail to notice such differences. As the findings of this study will show, these claims are not precise, as many nonlinguist respondents were able to identify subtle linguistic distinctions among QA speakers, which adds further support to the importance of PD in linguistic description and analysis.

A number of noticeable linguistic features distinguish QA from other varieties in Najdi Arabic. According to Al Ubudi (1979), the most distinctive and salient features of QA

\footnotetext{
${ }^{2}$ The Saudi government launched a program in the early 20th century to settle Bedouin tribes in sedentary dwellings across Saudi Arabia. This program has impacted the social, linguistic, and cultural life of these tribal peoples, as well as the areas in which they have settled. In Qassim, most settled Bedouins were from the tribes of Harb, Muțair, Rashid, 'Utaiba, and 'Anizah.

${ }^{3} \mathrm{Al}$ Jawa is a cluster of small towns almost $30 \mathrm{~km}$ northwest of Buraydah, right on the Buraydah-Ha'il highway. Administratively, it is considered an independent governorate, with Uyun Al Jawa as its main city. Linguistically, the people there speak with their own accent, with a slight local variation, particularly in the town of Uthal, as reported by some respondents (see Al-Washmi 1988, for a detailed account of its history and culture).

${ }^{4}$ Like Al Jawa, Al Asyah is formed by a cluster of towns that stretches for $25 \mathrm{~km}$ on one road between $\mathrm{Al}$ Asyah and Qiba (north of Qassim). Linguistically, we are referring to the general dialect spoken in all of these towns; there are slight differences, however, as reported by some respondents (see Al-Fuhaid 2009, for a detailed account).
} 
are: (1) deletion of $/ a /$ in the singular object feminine suffix $-h a,(2)$ backing of the thirdperson masculine object/possessive pronoun -ah to be /-uh/, and (3) deletion of /-i/ in the first object pronoun -ni. All of these QA features are also shared by the Ha'il dialect in the north, as they were presumably preserved from the dialect of the ancient Arab tribe Tay'. As such, the QA and the Ha'il dialect are classified as representing the northern division of Najdi Arabic varieties. However, there are other linguistic features, particularly phonological and lexical ones, that distinguish QA from the Ha'il dialect, but are shared with the southern dialects of Najdi Arabic in Riyadh, Sudair, and al-Washim (see Al-Aruk 2015 for a detailed account of QA's linguistic features).

In short, while most published works about QA by traditional dialectologists were concerned with the description of the dialect and comparing it with other neighboring dialects, none of these studies has attempted to describe the variation within this dialect from production or perception-based approaches. Moreover, no previous attempt has been made to document variation in the use of QA by social groups such as age, gender, educational level, etc. Therefore, this study attempts to fill this gap in the literature by shedding light on the perceived regional variation in the use of QA by age and gender groups.

\section{Methodology}

\subsection{Respondents}

A total of 289 respondents were selected to participate in the present study. The main selection criteria were that spoke QA and had spent most of their life in Qassim. The reason for these criteria was to ensure that respondents had concrete knowledge of the dialect in question and its perceived dialectical variation, as there are speakers of other varieties in Qassim, particularly tribal dialects. However, the first examination of the collected data revealed that only 240 surveys could be included in the analysis, as 49 surveys either had ambiguous demographic information or no map details. With regard to 
respondents' sex, they were almost balanced, 121 (50.5\%) were men and 119 (49.5\%) were women. As for age, respondents were between the ages of 13-86, divided into three age groups: older (22) 53-86 years old, middle-aged (89) 30-47 years old, and younger (129) 13-25 years old, reflecting to a great extent the age distribution of the Qassim population according to the 2010 National Census (see Tables 1-2 for detailed descriptions of respondents' age, city affiliation, and sex backgrounds).

\subsection{Elicitation tasks of perceptions}

To better understand nonlinguists' mental representations of the regional linguistic variation in the use of QA within Qassim, two PD techniques were employed: draw-a-map and labeling tasks. First, respondents were given a minimally detailed map of Qassim and were instructed to draw lines or circles around areas they considered to be dialect regions. The use of a minimalistic map was based on previous studies' findings (cf. CukorAvila et al. 2012, Jeon 2013) that additional geographic information on maps has influenced respondents' perceptions of where dialect areas exist. Second, respondents were asked to label the perceived dialect varieties with ideological evaluations, including labels or stereotypical features of speech. As stated earlier, the current study will be limited to data collected from the first task: dialect areas identification. Respondents' demographic information was also collected, including age, sex, place of birth, and place of residence in Qassim. Age information was later classified into three predetermined groups - older, middle-aged, and younger - to make comparisons among respondents' maps. All tasks were conducted in Arabic, both for the survey as well as the procedural instructions and explanations. Collection of surveys with male respondents was carried out by the author, whereas female assistants collected the surveys with female respondents. Figures 1-2 provide examples of respondents' hand-maps. 


\begin{tabular}{lcl} 
City & \# of Respondents & \% of Total \\
\hline Buraydah & 126 & $52.5 \%$ \\
Unayzah & 33 & $13.75 \%$ \\
Ar Rass & 30 & $12.5 \%$ \\
Al Bukayriyah & 10 & $4.5 \%$ \\
Al Mithnab & 10 & $4.5 \%$ \\
Al Badayea & 10 & $4.5 \%$ \\
Riyadh Al Khabra & 6 & $2.5 \%$ \\
Al Asyah & 6 & $2.5 \%$ \\
Al Jawa & 5 & $2 \%$ \\
Ash Shimasiyah & 4 & $1.65 \%$ \\
TOTAL & 240 & $100 \%$
\end{tabular}

Table 1. Distribution of respondents by city $(n=240)$.

\begin{tabular}{lllll} 
Group & Men & Women & Total & $\%$ \\
\hline Older & 11 & 11 & 22 & $9.1 \%$ \\
Middle-aged & 45 & 44 & 89 & $37 \%$ \\
Younger & 65 & 64 & 129 & $53.7 \%$ \\
Total & $121(50.5 \%)$ & $119(49.5 \%)$ & 240 & \\
\hline \hline
\end{tabular}

Table 2. Distribution of respondents by age and sex $(n=240)$.

\subsection{Data analysis}

Given the capabilities that GIS can add to PD research (cf. Montgomery \& Stoeckle 2013), particularly in aggregating and querying the geographic data identified in respondents' hand-drawn maps, the present study incorporated GIS software, namely ArcGIS 10.5.1, drawing on the data analysis procedures described in Evans $(2011,2013)$. Specifically, the following steps were applied: (1) Digitizing hand-drawn maps by scanning them and then georeferencing the "control points" on the scanned maps with a defined geographic coordinate system of Qassim; (2) Tracing all perceived dialect areas drawn on each respondent's map as a "polygon features" in the GIS software; (3) Adding social information as well as qualitative comments provided by each respondent as attributes for each polygon; (4) Creating composite heat maps by aggregating all maps and then calculating frequencies of overlapping "polygons" as percentages using values from the 
"attribute table." For the purpose of the present study, these composite maps include the most salient perceived dialect areas by age and gender groups, as well as the most frequent qualitative comments identified by the same social groups.

\section{Results}

It would be prudent to go over the dialect areas identified by all respondents to get an overall picture of respondents' placement and extent of all identified dialect areas before presenting the age and sex detailed results. Map 2 demonstrates a composite map of the dialect areas marked on all 240 hand-drawn maps. It also shows the agreement levels among respondents on dialect areas' saliency by combining the overlapping areas and displaying percentages of their agreement levels. As shown in the map legend, dialect areas marked with the darkest color indicates that they have the highest level of agreement among respondents, whereas areas with the lightest color are the least identified. For example, dialect areas in Buraydah and Unayzah are the darkest dialect areas on the map, representing an agreement level up to $90 \%$ of all respondents. Whereas the dialect areas associated with Al Mithnab and An Nabhaniyah were the least identified areas by agreement level up to $29 \%$ of all respondents.

Overall, 10 dialect areas have been marked by all respondents with different levels of frequency. The most salient dialect areas were marked in the dialect areas of Unayzah and Buraydah, followed by Ar Rass. The next most salient area included four cities combined in the middle of Qassim, namely Al Bukayriyah, Al Khabra, Riyadh Al Khabra, and Al Badayea. This area will henceforth be called the Mid-Qassim dialect. In a similar rate, two dialect areas in the northern part of Qassim have been identified in Al Jawa and Al Asyah, and a dialect area in Ash Shimasiyah in the eastern part of Qassim. A dialect area not clearly shown on the map was identified in the western side of Buraydah, locally called Al Khuboob. The least frequently identified dialect areas were located in Al Mithnab, south of Qassim, and in An Nabhaniyah, in the western end of the Qassimi dialect areas. 
The analysis of composite maps clearly revealed that both age and gender have an effect on respondents' perceptions of dialect boundaries. This is evident by comparing the dialect areas identified by each age and sex group with each other and with the composite map of dialect areas by respondents, as shown in Map 2. With regard to age, older respondents identified relatively fewer dialect areas, focusing mostly on those associated with main cities' dialects. Middle-aged and younger respondents identified more dialect areas, respectively. In terms of sex comparison, male respondents identified smaller and more differentiated dialect areas than female respondents do. The next sections will present a detailed description of the results pertaining to each age and sex group as well as age and sex interactions, with an attempt to suggest possible explanations.

\subsection{Age-groups' perceptions of dialect boundaries}

\subsubsection{Older respondents' perceptions}

As illustrated in Map 3, older respondents were found to have the lowest awareness of language variation in QA relative to other age groups in terms of number and size of dialect areas identified. The most salient dialect areas were focused on the main cities dialects, including Buraydah and Unayzah, followed by Ar Rass. This pattern is identical to that identified by all respondents, as shown in Map 2. Smaller dialects such as those associated with areas identified in mid-Qassim and An Nabhaniyah were almost not recognized by older respondents. The salience of dialect areas around Buraydah, namely Ash Shimasiyah to the east and Al Khuboob to the west of Buraydah as shown by the yellow color, is apparently related to the frequent identification of those areas as part of the larger view of the Buraydah dialect area. As noted by an older respondent from Buraydah, "the way people in Buraydah speak is not different from those in Ash Shimasiyah up to Al Bukayriyah to the west". 


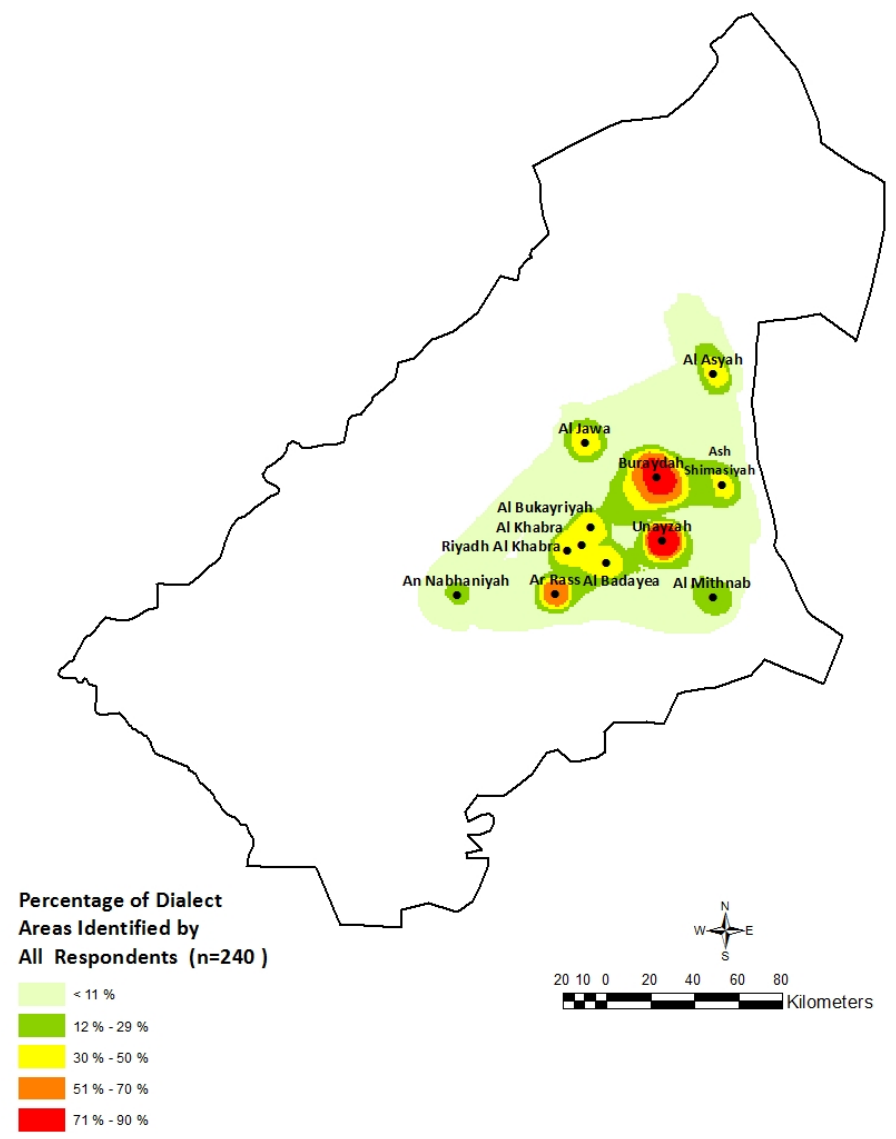

Map 2. Composite map of the most salient dialect areas identified by all respondents.

\subsubsection{Middle-aged respondents' perceptions}

Perceptions of dialect areas identified by middle-aged respondents have a higher level of granularity compared with other age groups' areas. As demonstrated in Map 4, the number of dialect areas identified by middle-aged respondents is almost similar to that identified by all respondents. The most noticeable difference lies in the frequent identification of the mid-Qassim area as shown by the orange color. This area was not salient to this level among other age groups. Additionally, middle-aged respondents recognized relatively smaller dialect areas, such as those in Al Mithnab in the south of Qassim, and An Nabhaniyah in the western end of Qassim. 
Dialectologia 26 (2021), 1-26.

ISSN: 2013-2247

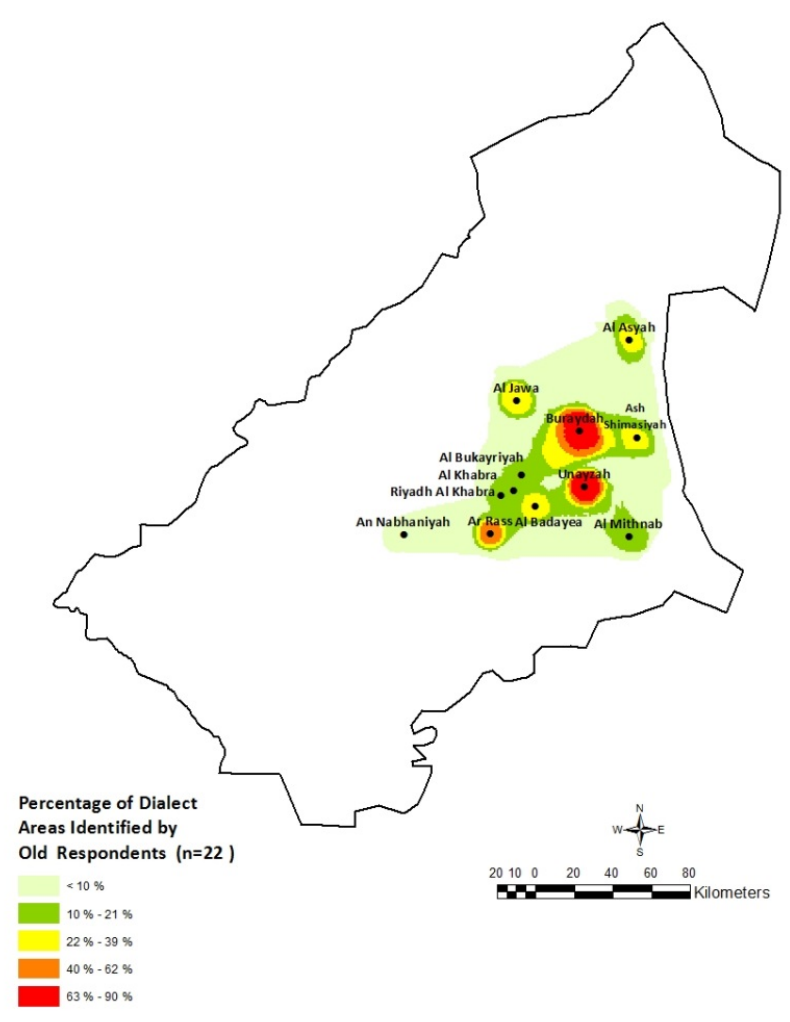

Map 3. Frequency of dialect areas identified by older respondents aged 53-86 years old.

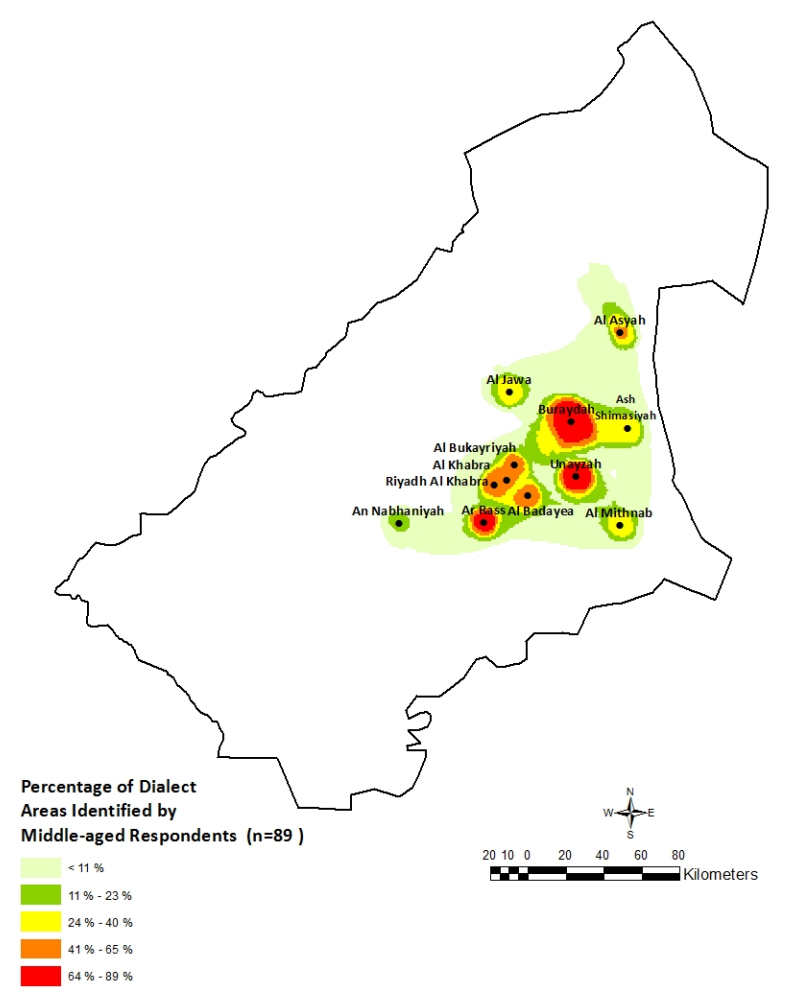

Map 4. Frequency of dialect areas identified by middle-aged respondents aged 30-47 years old. 


\subsubsection{Younger respondents' perceptions}

Compared with other age groups, younger respondents' dialect boundaries appeared different in terms of number, frequency, and size. As illustrated in Map 5, younger respondents identified fewer (six) dialect areas than those recognized by middleaged (10), but relatively more than older respondents. With regard to frequency, younger respondents identified the dialect areas of Al Asyah and Al Jawa with higher frequency of saliency than both older and middle-aged respondents, as shown by the orange and red colors, respectively. The dialect area of Mid-Qassim is also salient to younger respondents, as shown in the yellow color in the middle of Qassim. These results suggest that while older respondents still perceive language variation in QA to be mainly associated with the three largest cities in Qassim, many middle-aged and younger respondents perceive variation to include more salient areas with smaller space.

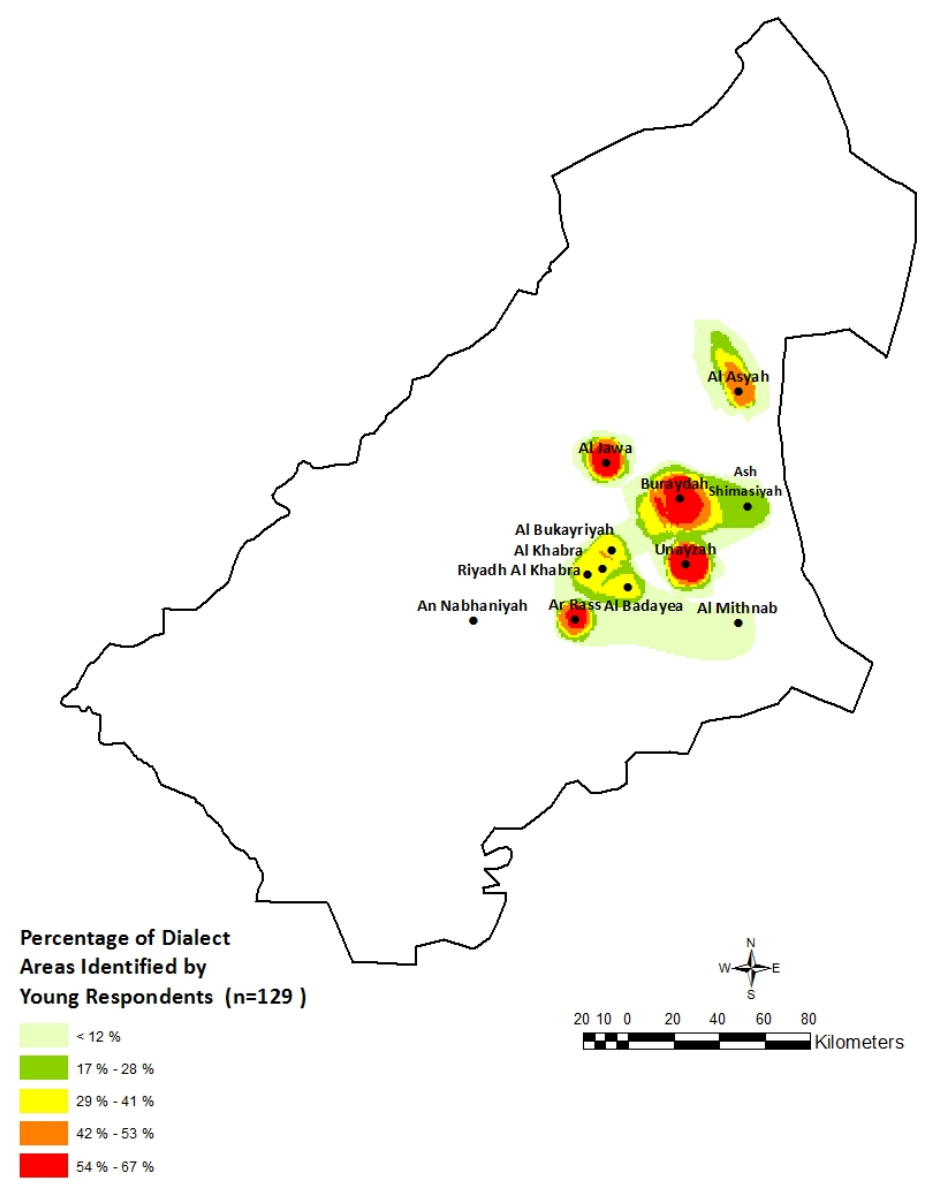

Map 5. Frequency of dialect areas identified by younger respondents aged 13-25 years old. 


\subsection{Sex-based differences in perceiving dialect boundaries}

Analysis of composite maps, as demonstrated in Map 6 for men and Map 7 for women, indicates that men distinguish more salient dialect areas (10) with a higher frequency of identification for relatively fewer salient dialects, including Mid-Qassim and Al Mithnab areas, as shown in the orange and yellow color, respectively. Female respondents, on the other hand, distinguished fewer salient areas (six) consisting of the three large cities in Qassim, namely Buraydah, Unayzah, and Ar Rass, as well as other dialects, but with less frequency of salience, as marked by the green color for Al Mithnab, Ash Shimasiyah, and Al Khuboob. This pattern of results suggests that men perceive linguistic variation with higher levels of granularity than women.

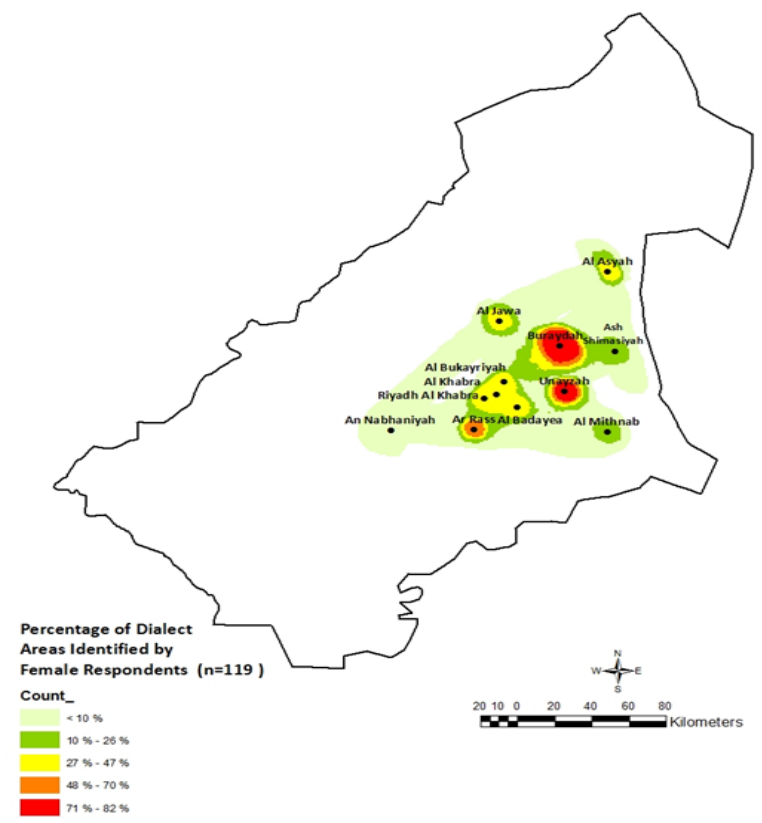

Map 6. Frequency of dialect areas identified by female respondents.

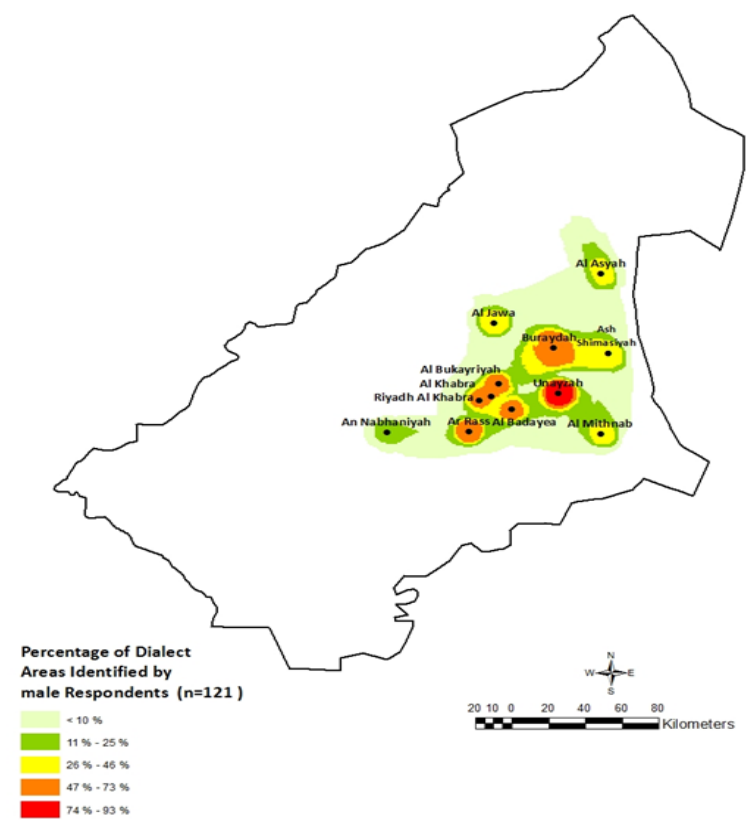

Map 7. Frequency of dialect areas identified by male respondents.

\subsection{Age and sex interaction}

To explore a possible interaction between age and sex on dialect perceptions, additional composite maps were created by stratifying the data by respondents' age and sex as the following groups: younger men, younger women, middle-aged men, middle- 
aged women, older men, and older women. Maps 8 to 12 show the frequency of areas identified by each group. Analysis of these composite maps suggests that the age-by-sex interaction also has an effect on respondents' perceptions of linguistic variation in QA. For example, by comparing the composite maps of those groups, it is evident that older female respondents identified the fewest dialect areas among all other groups. On the other hand, middle-aged men distinguished the greatest number of dialect areas, as shown by the number of dialect areas as well as the darkest color of dialect areas identified.

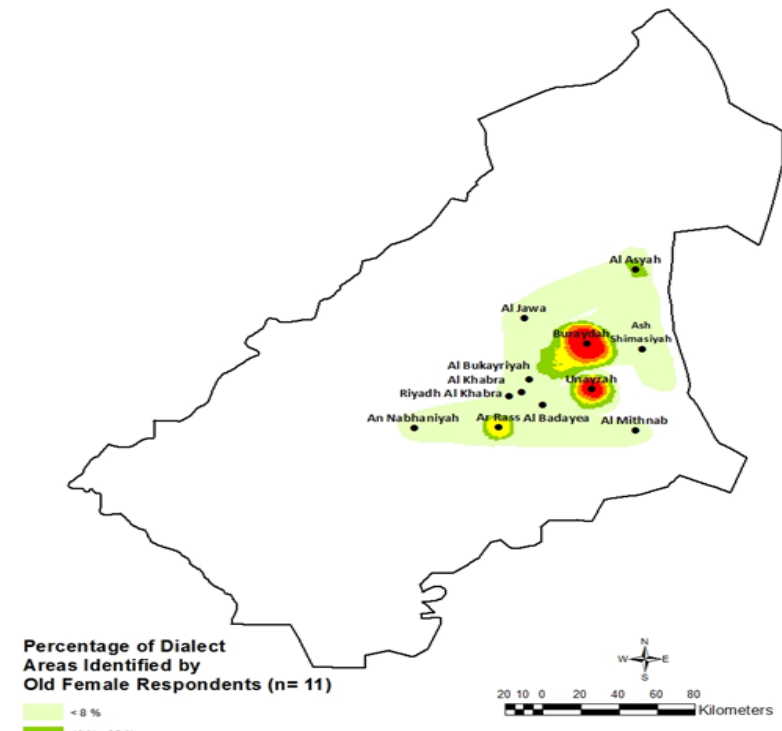

$<8 \%$
$10 \% .25 \%$

$285.46 \%$

$74 \times-97 \%$

Map 8. Frequency of dialect areas

identified by old female respondents.

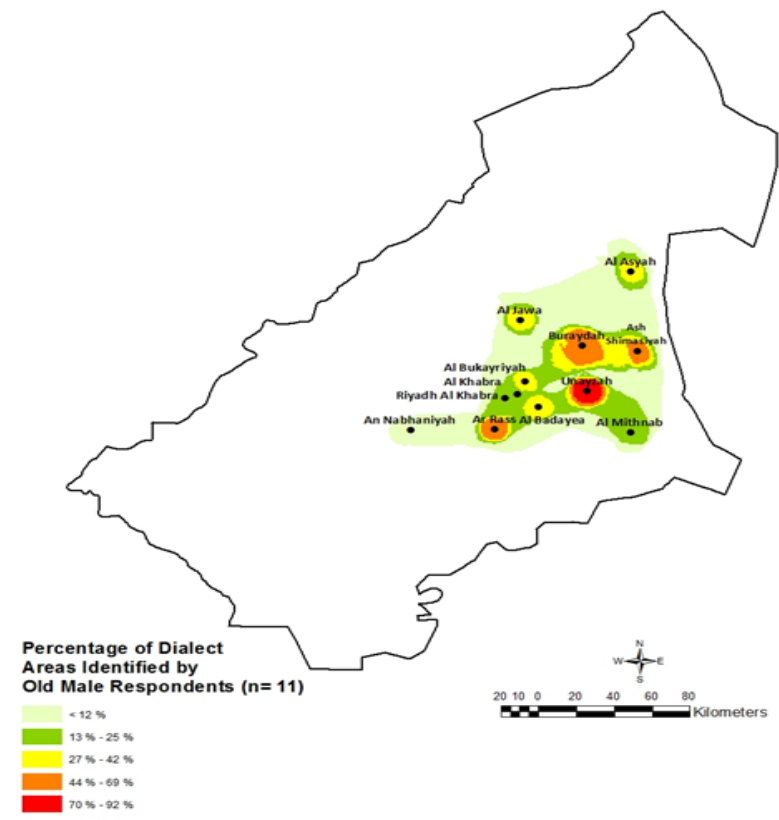

Map 9. Frequency of dialect areas identified by old male respondents. 


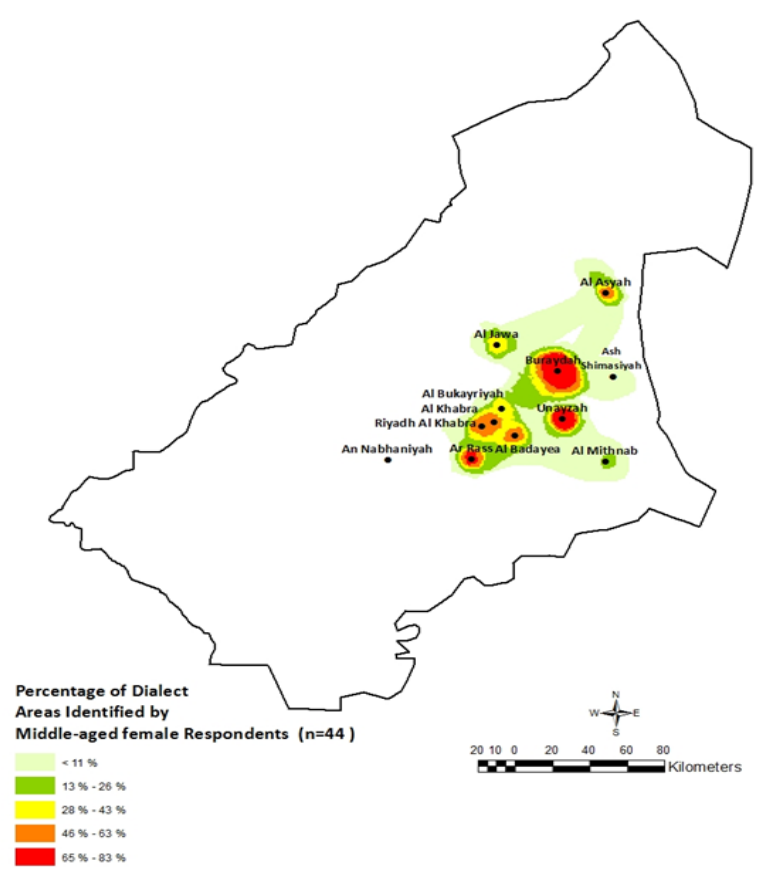

Map 10. Frequency of dialect areas identified by middle-aged female respondents.

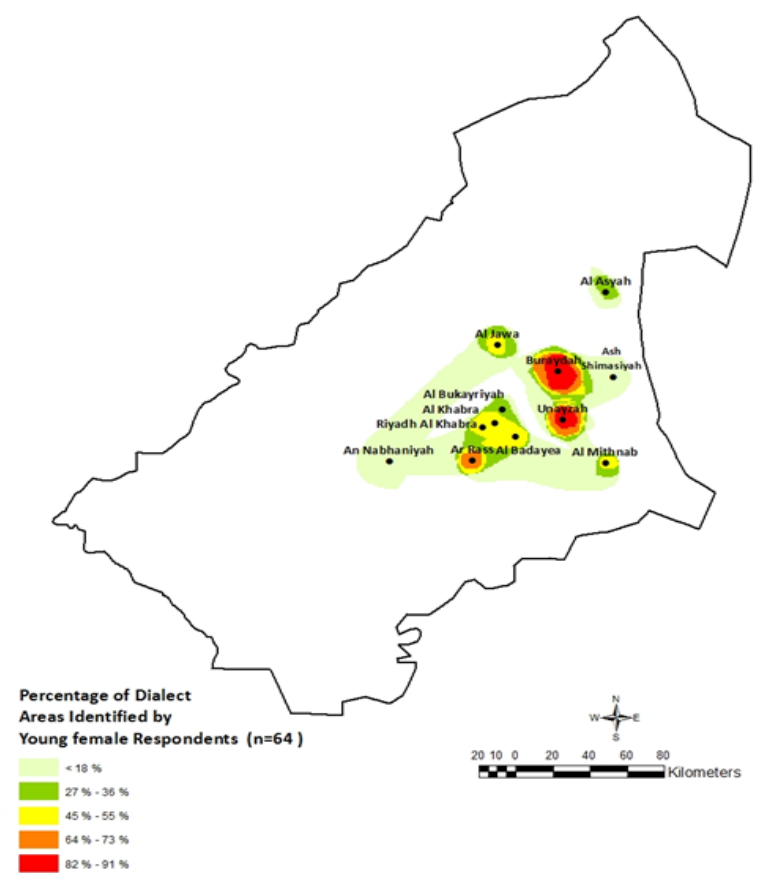

Map 12. Frequency of dialect areas identified by young female respondents.

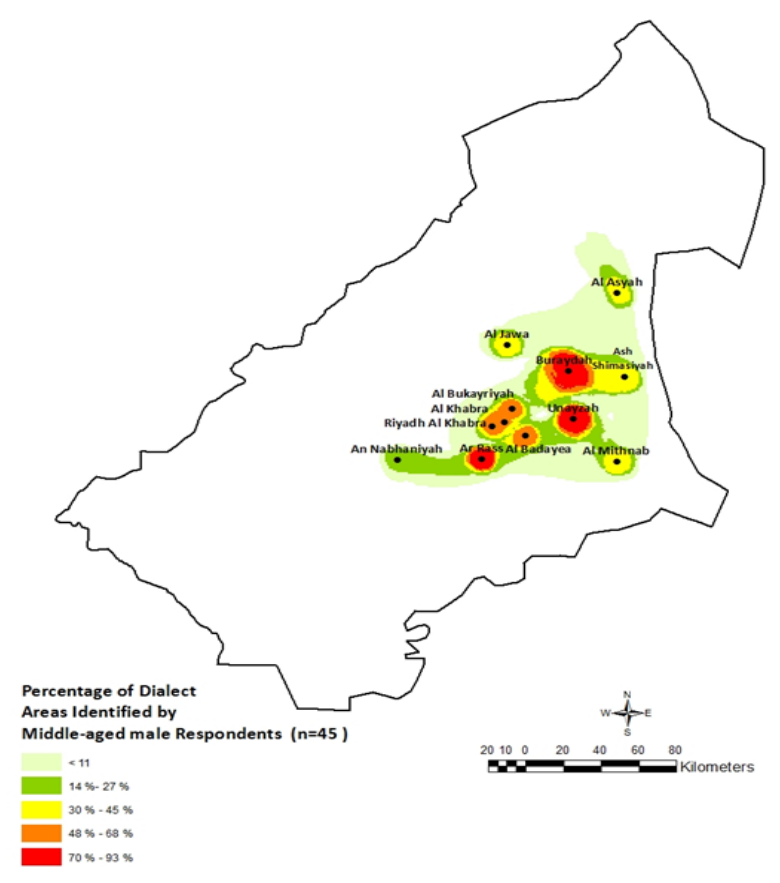

Map 11. Frequency of dialect areas identified by middle-aged male respondents.

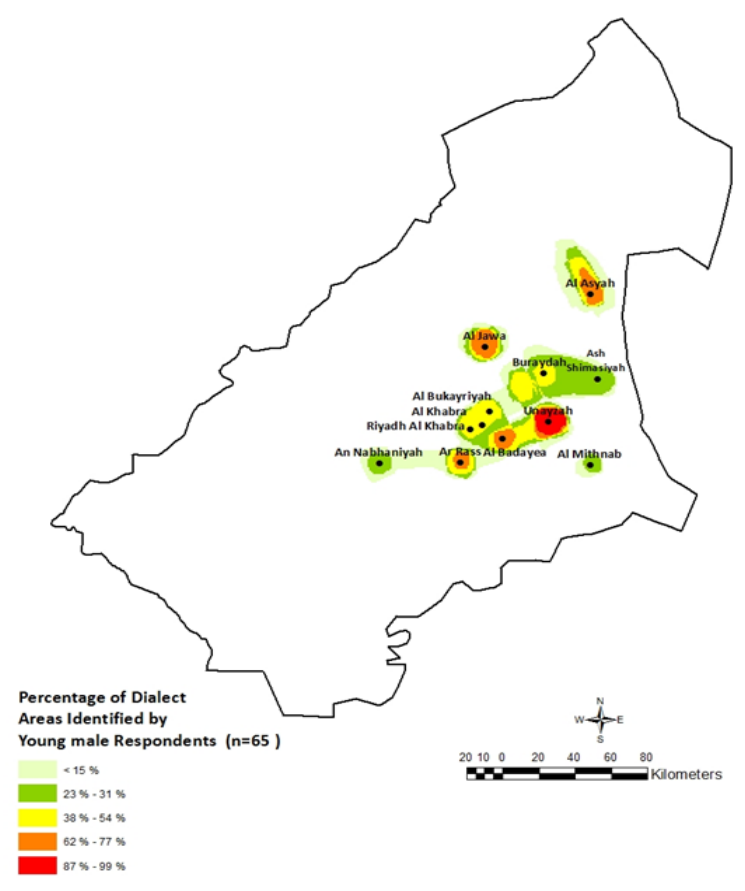

Map 13. Frequency of dialect areas identified by young male respondents. 


\section{Discussion and conclusions}

The current findings suggest that the respondents' age and sex have an effect on their perceptions of the linguistic landscape of QA in Qassim. These results are consistent with Jeon's (2013) findings with respect to overall age and sex influence on South Korean respondents' perceived identification of dialect areas in Korea. However, the current results differ considerably from Jeon's study in terms of the differences among age and sex groups in their perceived dialect variation. Whereas Koreans' perceptions of dialect areas correlate with respondents' age, the current results revealed that middle-aged respondents distinguished the most dialect areas, followed by younger respondents and then the oldest. With regard to sex, in the current study men rather than women identified the most and detailed dialect variation, which differs from Jeon's study.

The present pattern of age and sex variation in perceiving dialect boundaries can be better understood by considering the social realities and social roles that age and sex groups perform within their local communities. For example, the present sex-difference in identifying dialect variation can be attributed to the conservative and traditional society in Qassim where men generally have higher levels of social and geographical mobility. This situation, in turn, provides men with more exposure and linguistic experience in distinguishing dialect variation than women. This account is consistent with previous production-based experimental studies that demonstrated that exposure to different varieties through geographical mobility affects nonlinguists' perceptions of dialect categorization and identification (e.g., Evans \& Iverson 2004; Clopper \& Pisoni 2004, 2006).

The same explanation can account for the differences among age-groups in their perceived dialect areas identification. Compared with the other two-age groups, middleaged respondents (30-47 years old) likely have the highest levels of social and geographical mobility as a result of their increasing business and travel, particularly due to the drastic and rapid socioeconomic changes that Saudi Arabia has undergone in the past 50 years that accounts for most of their lives. During this period, people in Saudi Arabia have witnessed changes in all aspects of their lives, including geographic mobility, contact, and urbanization. Thus, middle-aged respondents have presumably more prior 
linguistic experience with dialect variation, and consequently they have a greater ability to distinguish dialect variation than the other age groups. On the other hand, younger respondents (13-25 years old) have relatively less experience and exposure to dialect variation; all were either school or university students, and thus they are not likely to have the same linguistic experience and mobility of middle-aged respondents. As for older respondents (53-86 years old), they apparently have not been influenced by the socioeconomic changes like the other two age groups, as they were born and raised before these changes took place. This resulted in making their linguistic experience dialect variation in QA more limited. This is more evident in the pattern of perceived dialect variation by older female respondents who identified just main city dialects.

In short, the present study contributes to the Arabic sociolinguistics discipline of perceptual dialectology by extending our understanding of the interplay between social differentiation and perceptions of language variation. This work can be considered the first step in a broad field that has plenty of areas for further exploration, either in Arabic or in other languages. Future studies need to examine in more depth, for example, the effect of other social differences such as educational level, social class, local affiliation, urbanization, and ethnicity. The effects of social and geographic mobility mentioned in the discussion also merit further detailed examination.

\section{References}

AL-ARUK, Badriyah (2015) Lahjat al-Qașīm wa-șilatuhā bi-al-fușhá [Qassimi Dialect and its relation to Classical Arabic fusha], Buraydah, Saudi Arabia: Qassim Cultural Club in Buraydah.

AL JUMAAH, Khalid (2017) Mu'jam al-Asmaa al-mu'annathah al-samāî̃yah fí al-Lahjah al-Qașīmīyah al-mu'āșirah [Directory of Oral Feminine Nouns in Contemporary Qassimi Dialect], Buraydah, Saudi Arabia: Qassim Cultural Club in Buraydah.

AlRUMAIH, Ahmad (2002) Najdi Perceptions of Saudi Regional Speech, Unpublished MA thesis, Michigan State University, East Lansing, Michigan, USA. 
AL-RoJaIE, Yousef (2013) "Regional dialect leveling in Najdi Arabic: The case of the deaffrication of [k] in the Qașīmī dialect", Language Variation and Change, 25, 43-63.

AL-UBUDI, Muhammad Nassir (1979) al-Mu'jam al-jughrāfí lil-bilād al-'Arabīyah al-Sa'ūdīyah: bilād al-Qașim [Geographic Directory of Saudi Arabia: the Qassim Province], Riyadh, Saudi Arabia: Al-Yamāmah for Translation \& Publishing.

Benson, Erica J. (2003) "Folk Linguistic Perceptions and the Mapping of Dialect Boundaries", American Speech, 78, 307-330.

Bucholtz, Mary, Nancy Bermudez, Victor Fung, Lisa EdWARds \& Rosalva Vargas (2007) "Hella Nor Cal Or Totally So Cal?: The Perceptual Dialectology Of California", Journal of English Linguistics, 35, 325-352.

Bucholtz, Mary, Nancy Bermudez, Victor Fung, Rosalva Vargas \& Lisa Edwards (2008) "The Normative North and the Stigmatized South: Ideology and Methodology in the Perceptual Dialectology of California", Journal of English Linguistics, 36, 62-87.

EVANS, Bronwen G. \& Paul IVERSON (2004) "Vowel normalization for accent: An investigation of best exemplar locations in northern and southern British English sentences", Journal of the Acoustical Society of America, 115, 352-361.

ClOPPER, Cynthia G. \& David B. PISONI (2004) "Homebodies and army brats: Some effects of early linguistic experience and residential history on dialect categorization", Language Variation and Change, 16, 31-48.

CLOPPER, Cynthia G. \& David B. PISONI (2006) "Effects of region of origin and geographic mobility on perceptual dialect categorization", Language Variation and Change, 18, 193-221.

CRAMER, Jennifer (2010) The effect of borders on the linguistic production and perception of regional identity in Louisville, Kentucky, Unpublished Doctoral dissertation, University of Illinois, Urban-Champions, IL, USA.

Cukor-Avila, Patricia, Lisa Jeon, Patricia C. ReCtor, Chetan TIWARI \& Zak SHelton (2012) “Texas - It's like a whole nuther country: Mapping Texans 'perceptions of dialect variation in the Lone Star state", in Proceedings from the Twentieth Annual Symposium about Language and Society, Austin, TX: Texas Linguistics Forum, 11-19.

<http://salsa.ling.utexas.edu/proceedings/2012/cukoravilaetal.pdf >.

DEMIRCI, Mahide (2002) "Gender Differences in the Perception of Turkish Regional Dialects", in Daniel Long \& Dennis. R. Preston (eds.), Handbook of Perceptual Dialectology, vol. 2, Amsterdam / Philadelphia: John Benjamins, 41-50.

DemIRCI, Mahide \& Brian KleINER (1998) "Gender and Age-based Variation in the Perception of Turkish Dialects", Language Awareness, 7, 206-222. 
ECKERT, Penelope (2000) Linguistic Variation as Social Practice: The Linguistic Construction of Identity in Belten High. Malden. MA: Blackwell.

Evans, Betsy (2011) "Seattletonian to faux hick: Perceptions of English in Washington State", American Speech, 86, 384-413.

Evans, Betsy (2013) "Seattle to Spokane: Mapping perceptions of English in Washington State", Journal of English Linguistics, 41, 268-291.

HACHIMI, Atiqa (2015) "Good Arabic, bad Arabic: Mapping language ideologies in the Arabicspeaking world", Zeitschrift Für Arabische Linguistik, 61, 35-70.

HARTLEY, Laura (1999) "A View from the West: Perceptions of U.S. Dialects by Oregon Residents", in Dennis R. Preston (ed.), Handbook of Perceptual Dialectology, 1, Amsterdam, Netherlands: Benjamins, 315-332.

INOUE, Fumio (1996) "Subjective dialect division in Great Britain", American Speech, 71, 142-161.

JEON, Lisa (2013) Drawing boundaries and revealing language attitudes: Mapping perceptions of dialects in Korea, Unpublished MA thesis, North Texas University, Denton, Texas, USA.

KUIPER, Lawrence (2005) "Perception is reality: Parisian and Provencal perceptions of regional varieties of French", Journal of Sociolinguistics, 9/1, 28-52.

LABOV, William (2001) Principles of linguistic change. volume 2: Social factors. Malden, MA/Oxford: Blackwell.

LONG, Danial (1999) "Geographical perceptions of Japanese dialect regions", In Dennis Preston (Ed.), Handbook of Perceptual Dialectology, Amsterdam: John Benjamins, 177-198.

Montgomery, Chris \& Philipp StOeCKLE (2013) “Geographic information systems and perceptual dialectology: a method for processing draw-a-map data", Journal of Linguistic Geography 1, 52-85.

NiedZIELSKI, Nancy A. \& Dennis R. Preston (2000) Folk Linguistics, Berlin: Mouton de Gruyter.

PRESTON, Dennis R. (1986) “Five visions of America”, Language in Society, 15, 221-240.

PRESTON, Dennis R. (1989) Perceptual dialectology: Nonlinguists' views of areal linguistics. Providence, Foris

PRESTON, Dennis R. (1996) "Whaddayaknow": The modes of folk linguistic awareness", Language Awareness, 5, 40-74.

PRESTON, Dennis R. (ed.) (1999) Handbook of Perceptual Dialectology, 1, Amsterdam: John Benjamins.

PRESTON, Dennis R. (2017) "Perceptual dialectology", in C. Boberg, J. Nerbonne \& D. Watt (eds.), Handbook of dialectology, Hoboken, NJ: Wiley-Blackwell. 
Theodoropoulou, Irene \& Joseph Tyler (2014) "Perceptual Dialectology of the Arab World", AlArabiyya, 47, 21-39.

YAN, Qingyang (2015) "The perceptual categorization of Enshi Mandarin regional varieties", Journal of Linguistic Geography, 3, 1-19. 